\title{
Os modos de conhecimento da ciência e da arte em Schopenhauer e Freud
}

\section{The moods of knowledge of science and art in Schopenhauer and in Freud}

\author{
Eduardo Ribeiro da Fonseca \\ Professor do Programa de Pós-Graduação em Filosofia da PUCPR \\ Membro da Seção Brasileira da Schopenhauer-Gesellschaft \\ E-mail: eduardorfonseca@uol.com.br
}

\begin{abstract}
Resumo: Nosso texto pretende evidenciar aspectos da relação entre arte, filosofia e conhecimento empírico na filosofia de Schopenhauer, tomando como exemplo as narrativas dos casos clínicos de Freud e a sua consideração, simultaneamente como peças de ficção e como narrativas factuais de processos clínicos ligados à psicologia, de um modo geral, e aos "Estudos sobre a histeria" (1893-1895), de um modo particular.
\end{abstract}

Palavras-chave: Intuição; Racionalidade; Ideia; Narrativa; Ciência.

\begin{abstract}
Our paper aims to highlight aspects of the relationship between art, philosophy and empirical knowledge in Schopenhauer's philosophy, taking as an example the narratives of Freud's clinical cases and their consideration, both as pieces of fiction and as factual narratives of clinical processes linked to psychology, in general, and the "Studies on hysteria" (1893-1895), in a particular way.
\end{abstract}

Keywords: Intuition; Rationality; Idea; Narrative; Science. 


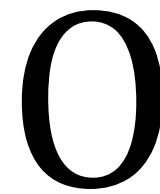
estudo do Livro III dos “Complementos" (Ergänzungen) de $1844^{1}$ à obra magna de Schopenhauer (especialmente os capítulos XXIX, XXX, XXXI e XXXII) nos leva à consideração de uma importante distinção entre modos de conhecimento de acordo com o princípio de razão suficiente e independente do princípio de razão suficiente. Além das observações feitas em capítulos precedentes do Livro I $(2014,1)$ da mesma obra referentes à distinção entre conhecimento intuitivo e abstrato (especialmente de acordo com os capítulos II, V, VI e VII), que determina o contexto subjetivo do intelecto de acordo com o princípio de razão suficiente, no qual se ressalta a condição humana originária e natural de servidão à vontade, o intelecto aparece no terceiro livro, de acordo com outro ponto de vista, libertado ou emancipado momentaneamente do serviço da vontade $(2014,2$, p. 13). Logicamente, se escrevemos sobre complementos ao texto original, o mesmo objeto é tratado, segundo o autor, de modo suficiente no Tomo I, tratando-se, nos capítulos mencionados, de observações específicas e suplementares, mas que, em nosso modo de compreender, esclarecem melhor o ponto de vista da ciência em relação ao da arte e, especialmente, entram em conexão com certos pontos de vista da Psicanálise de Freud.

O que pretendemos expor através de exemplos da obra de Freud é que existem considerações psicanalíticas de certo modo correlatas (caso mantenhamos o perímetro adequado à extensão dos conceitos em um caso e em outro, bem como os objetivos específicos e particulares do psicanalista) acerca do problema da relação entre o modo de apreensão do gênio e o do cientista e de como Freud procura tirar partido dessa distinção em sua própria obra, no caso, os "Estudos sobre a Histeria", escritos em conjunto com Josef Breuer (1842-1925), bem como em outros lugares, especialmente nas cartas a Fliess e nos textos sobre arte e artistas.

\section{As inescrutáveis forças naturais: o pesquisador empírico como artista racional?}

${ }^{1}$ SCHOPENHAUER, A. MVR II (Tradução e notas de Eduardo Ribeiro da Fonseca). 
Freud acolhe aspectos relevantes do modelo kantiano de conceber a ciência e o papel do pesquisador empírico, especialmente no que concerne à distinção entre a observação direta do caso particular e a sua generalização em conceitos abstratos, o que implica, no mais das vezes, na elaboração de ficções heurísticas, que não são meras formulações racionais, mas mantém sua conexão com o mundo e com os objetos empíricos e, por assim dizer, preenchem as lacunas da experiência no âmbito da própria experiência para buscar uma unidade, permitindo uma organização no âmbito teórico através de hipóteses e de uma trama conceitual definida, ainda que provisória ${ }^{2}$. Tais ficções conceituais se encadeiam com conhecimentos obtidos diretamente da efetividade, mas sua realidade objetiva não poderia ser, dado o seu caráter ficcional, de maneira alguma, conhecida. Conforme escreve Kant, os conceitos da razão...

\begin{abstract}
...são meras ideias e, evidentemente, não têm objeto algum em alguma experiência, mas nem por isso designam objetos inventados que, ao mesmo tempo, fossem tomados por possíveis. Eles são pensados apenas problematicamente, para fundar na relação com eles (enquanto ficções heurísticas), princípios regulativos do uso sistemático do entendimento no campo da experiência. Partindo-se disso, eles são meros produtos do pensamento cuja possibilidade não é demonstrável e que, por isso, não podem, através de uma hipótese, ser colocados como fundamento da explicação dos fenômenos reais ${ }^{3}$.
\end{abstract}

Nesse sentido, o psicanalista vienense trabalha primariamente em dois planos ou níveis articulados entre si, o decididamente empírico, o da clínica, e o metapsicológico, que lhe complementa. Freud admite em carta a Einstein, que a metapsicologia precisa se afastar parcialmente do meramente observado e ultrapassar a fronteira do empírico, o que ele chama de mitologia da Psicanálise, o que inclui, naturalmente, fantasia e alguma ilusão. Para o psicanalista vienense tal movimento é imprescindível e circunscreve os limites da própria ciência,

\footnotetext{
2 LOPARIC, Z. "De Kant a Freud: Um roteiro". Campinas, Revista Natureza Humana v. 5, n. 1, primeiro semestre de 2003, p. 240. Esse artigo é de fundamental importância para a compreensão do tema da relação entre a clínica freudiana e sua superestrutura conceitual denominada Metapsicologia. Loparic escreve: "Seria permitido admitir hipóteses especulativas na ciência da natureza? Sim, responde Kant nesta obra, desde que elas sejam úteis na busca da formulação e da solução dos problemas empíricos (científicos)".

${ }^{3}$ KANT, Immanuel. Crítica da Razão Pura. Tradução e notas de Fernando Costa Mattos. Petrópolis: Vozes, 2016, p. 565.
} 
alimentando suas concepções heurísticas, não apenas em sua obra publicada, mas, mais ainda nas cartas enviadas aos seus discípulos. Como ele faz isso? Nossa hipótese é a de que ele formula seus conceitos metapsicológicos de natureza heurística não apenas como cientista empírico, mas também se admite como uma espécie de artista racional na generalização de seus dados empíricos no sentido schopenhaueriano, gerando, por assim dizer, no íntimo de sua teoria, abordagens de cunho mitológico em relação à natureza e à Humanidade e que tingem a teoria freudiana com as cores fortes da fantasia, que ele adota para melhor interpretar e organizar a profusão de dados empíricos que chegam a ele a partir das histórias individuais de seus analisandos. Na teoria dos Triebe isso fica evidente:

A teoria dos impulsos (Triebelehre) é, por assim dizer, nossa mitologia. Os impulsos são seres míticos, magníficos em sua indefinição. Em nosso trabalho, não podemos desprezá-los, nem por um só momento, uma vez que nunca estamos seguros de os estarmos vendo claramente. (...) Sempre se nos impôs a suspeita de que, por trás de todos os numerosos impulsos se esconda algo sério e grandioso, de que gostaríamos de nos aproximar com cautela 4 .

Mas, o que, nesse movimento, pode ser talvez melhor explicado levando em consideração o movimento do pensamento do filósofo de Frankfurt de um ponto de vista epistemológico?

Retomando o pensamento de Schopenhauer neste sentido observado acima, pode-se dizer que o intelecto dos animais em sua função natural conhece apenas as relações entre as coisas. ${ }^{5}$ Num primeiro sentido, trata-se da relação do próprio intelecto com a vontade, e, de modo complementar, trata-se da relação das coisas umas com as outras, sempre consideradas a partir de diferenças de grau entre os diversos seres naturais, dentre os quais a Humanidade se destaca de todas as

\footnotetext{
4 "Die Trieblehre ist sozusagen unsere Mythologie. Die Triebe sind mythische Wesen, großartig in ihrer Unbestimmtheit." (FREUD, S. Das Werk, Folge 32, Angst und Trieblehre, p. 529) [FREUD, S., 1933b, p. 119.] Freud se refere à teoria das pulsões como uma mitologia não apenas nas Novas conferências introdutórias, mas também na sua carta a Einstein: "Vielleicht haben Sie den Eindruck, unsere Theorien seien eine Art von Mythologie, nich teinmal eine erfreuliche in diesem Fall. Aber läuft nicht jede Naturwissenschaft auf eine solche Art von Mythologie hinaus? Geht es Ihnenheute in der Physikanders?" (FREUD, S. Das Werk, Warum Krieg?, p. 283) ["Talvez você tenha a impressão de que nossas teorias são um tipo de mitologia, no caso presente uma mitologia que nem mesmo é agradável. Mas toda ciência da natureza não volta a tal tipo de mitologia? Acontece, hoje, de maneira diferente para você, na física?" (1933b, p. 211)].

5 SCHOPENHAUER, A. MVR II, 2, p. 13.
} 
outras séries animais pela sua complexidade de relações. Mas, há também gradação entre as pessoas, pelo que ocorre uma variação subjetiva importante entre os graus mais baixos de servidão (Diensbarkeit) em relação à vontade, nos quais a relação entre as coisas é apenas indireta e os graus mais elevados, nos quais já aparece uma transição para o conhecimento objetivo, que é considerada independente dessa vontade subjetiva. Nesses níveis mais elevados, as relações entre as coisas não seriam mais mediadas, na opinião do filósofo, pelas relações subjetivas (as de acordo com o princípio de razão suficiente), tornando-se então objetivas, pelo que ocorre a liberação momentânea do serviço da vontade através de uma completa separação entre o ser em si mesmo e essas relações ${ }^{6}$. Isso permite, na linguagem do autor, conhecer aquilo que é essencial ao objeto, a sua simples forma (ou tipo) excluída do tempo ou sua espécie, correlato empírico dessa forma dado simultaneamente na experiência e no tempo. Essa forma considerada aqui não é de fato apenas aquilo que é tomado a partir de conceitos, portanto por intermédio da ciência ou do trabalho intelectual subjetivo do filósofo, mas é algo que se contempla na sua totalidade. Ideia e conceito são, portanto, semelhantes, na medida em que ambos refletem a tendência a reunir as intuições das características individuais naquilo que estas têm em comum, na sua unidade, que é restaurada no tempo tanto pela contemplação da ideia, independentemente do pensamento conceitual, isto é, da racionalidade, tomada então de um só golpe, já que a ela atribuímos existência e realidade, quanto pela abstração da faculdade de razão denominada conceito, que se configura através da linguagem filosófica ou científica?

O nosso conhecimento das coisas se move como que de modo pendular entre ideia e conceito, dependendo de nossa capacidade de apreensão objetiva e espontânea da efetividade, por um lado, e da nossa capacidade de abstração, por outro. Porém, para se chegar a este grau mais elevado de abstração, que faz espontaneamente a separação entre o conceito e a ideia, faz-se necessária, de acordo com o filósofo, uma preponderância temporária do intelecto sobre a vontade. 0 que se faz (1) artificialmente através da linguagem como uma transição

\footnotetext{
${ }^{6}$ SCHOPENHAUER, A. MVR II, 2, p. 14.

${ }^{7}$ Ibidem, p. 17.
} 
entre uma série de intuições sensíveis e um conceito (no domínio do conhecimento de acordo com o princípio de razão), (2) faz-se natural e espontaneamente através da contemplação da ideia (de modo independente do princípio de razão). 0 curioso é que, de um ponto de vista fisiológico, isso é descrito pelo filósofo como uma forte excitação da atividade intuitiva do cérebro ${ }^{8}$, sem qualquer excitação das inclinações ou afetos ligados ao restante do organismo (o cérebro é também uma vontade ${ }^{9}$ ). Se, (1) de um ponto de vista subjetivo, partimos de dentro e consideramos a consciência (de nós mesmos e das outras coisas) como o que é dado e, a partir dela, temos uma visão do mundo e da própria possibilidade da consciência e da vontade concebida como um querer que afirma (voluntas) e nega (noluntas) ${ }^{10}$ e se, de um ponto de vista objetivo, partimos do empírico como algo determinado, anatômico e fisiológico, por outro lado, (2) temos também a consideração a partir da contemplação da ideia platônica não mais como simples caso ou como uma generalização racional a partir de um conjunto de casos, mas como um acentuado movimento de atenção livremente desimpedida que permite o discernimento dos objetos não mais naquilo que se relaciona ao nosso querer ou não querer, ao nosso interesse pessoal, mas sim no que eles são independentes de sua relação com a nossa vontade, ao ponto de, nos cérebros mais "desenvolvidos e enérgicos", ocorrer um completo descolamento desse objeto que permite a "pura objetividade da intuição", que em si mesma "elimina a vontade da consciência, tornando as coisas diante de nós mais claras e distintas"11pelo que "conhecemos não mais a coisa individual propriamente dita, mas sim a ideia de sua espécie"12. Nesse caso, o verdadeiro objeto não é mais percebido por um sujeito do querer, mas sim por um "puro sujeito do conhecimento"13, ou "eterno olho do mundo"14, que é o sustentáculo do "mundo das ideias permanentes, ou seja, da objetidade adequada da vontade"15. Ou seja, o puro sujeito é "todas as coisas" na medida em que as

\footnotetext{
8 Ibidem, p. 19.

${ }^{9}$ SCHOPENHAUER, A. MVR II, 1, p. 403.

10 SCHOPENHAUER, A. MVR II, 2, p. 21.

11 SCHOPENHAUER, A. MVR II, 2, p. 20.

12 Ibidem, p. 22.

${ }^{13}$ Ibidem, p. 23

14 Ibidem, p. 25.

15 Idem.
} 
intui ${ }^{16}$. No mesmo sentido, a apreensão objetiva é a condição para o prazer ou gozo com os objetos artísticos, seja do ponto de vista do apreciador, seja do criador.

Em Freud, esse duplo movimento entre intuição e racionalidade (entendidas como um esforço consciente e ligado às nossas representações e ao concatenamento entre elas), e aquilo que sendo ainda intuição, não depende do princípio de razão, é constante, e pode ser observado desde o princípio de suas formulações metapsicológicas. Faz-se a ressalva de que, na compreensão de Freud, a interpretação de Schopenhauer acerca do puro sujeito do conhecimento seria apenas uma inclinação sublimada do desejo nesse sentido, exatamente de acordo com a interpretação de Nietzsche (na Genealogia da Moral). Se, em Schopenhauer, o cérebro e o sistema nervoso aparecem como uma espécie de parasita em relação ao restante do organismo, em Freud não há tal separação, a não ser do ponto de vista do recalque, que Schopenhauer também percebeu de modo inaugural, mas não deu a ele suficiente relevância na vida psíquica comum. Nesse sentido, o prazer derivado da criação ou apreciação de objetos artísticos é ainda um prazer ligado à libido, essa energia de caráter sexual postulada pelo psicanalista. Assim, a explicação de Schopenhauer é matizada e encontramos um sentido psicanalítico para o nosso prazer com os objetos artísticos. No fundo, o efeito do belo na representação artística e o gozo do puro sujeito do conhecimento ainda seriam formas sublimadas do querer em relação ao qual Schopenhauer é ambíguo, pois admitirá os ardis do querer sexual inconsciente (especialmente na Metafísica do amor sexual) e que a vontade desaparece apenas da consciência (na Metafísica do belo), mas, por outro lado, recusa-se terminantemente a considerar a afirmação da vida e da sexualidade através do objeto artístico. Essa ambiguidade mencionada acima fica patente quando Schopenhauer diz coisas como que o gênio é condicionado por um temperamento apaixonado e que paixões muito poderosas são uma condição para o gênio e estão ligadas à apreensão viva das coisas, produzindo com isto uma grande excitação dos afetos, que é perturbadora.

Se o conhecimento mais perfeito, a apreensão puramente objetiva do mundo, isto é, a apreensão do gênio, é condicionada por um silenciamento da vontade tão profundo que, enquanto dura, mesmo a individualidade desaparece da

16 Idem. 
consciência, e o homem permanece puro sujeito do conhecimento, que é o correlato da Ideia, por outro lado, paradoxalmente, tudo isso precisa ser sustentado por uma vontade forte. Há, portanto, um antagonismo entre um caráter apaixonado e uma atividade sublimatória e que, para Freud, provavelmente representaria uma forma disfarçada de afirmação da sexualidade através de uma mudança de objeto (que implicaria numa renúncia do objeto original e em um grau de satisfação quantitaivamente menor em relação ao objeto original, o que explica também a qualidade afetiva do gozo estético descrito pelo filósofo).

De qualquer modo, se deixamos um pouco de lado essas situações mais complexas e ainda pouco abordadas no íntimo da filosofia de Schopenhauer e vamos até a obra de Freud para ver como ele próprio manejava com essas noções schopenhauereanas de um conhecimento intuitivo em duas modalidades de acordo ou independente do princípio de razão, seja nas obras publicadas, seja nas cartas endereçadas ao seu amigo Fliess, vemos algumas coisas interessantes e que podemos comentar aqui para esclarecer a importância clínica e teórica dos problemas pontuados por Schopenhauer nas relações entre intelecto e desejo e entre intelecto e visões subjetiva (a da ciência) e objetiva do mundo (a do filósofo e do artista geniais), mostrando que Freud também postula de certa forma uma reunião das duas formas de intuição em um mesmo movimento no âmbito do intelecto de uma mesma pessoa.Decerto ponto de vista, Freud parece se encaixar melhor na definição de filósofo dada por Schopenhauer, do que na de pesquisador empírico, com a exceção notável de que ele é capaz também de produzir os próprios dados empíricos fornecidos à sua análise como artista racional.

\section{A distinção entre uma descrição puramente factual e uma narrativa literária no âmbito dos estudos de casos psicanalíticos realizados por Freud e suas consequências}

A leitura do texto de Ernst Kris que aparece como prólogo às cartas à Fliess encontradas por Marie Bonaparte é bastante reveladora daquilo que podemos chamar talvez de certa mistificação em torno de Freud como homem de ciência, ainda que o texto, no mais muito interessante, apenas relutantemente admita aquilo que o próprio Freud reconhece às vezes, e que, genericamente, podemos 
chamar de diversidade de pontos de vista de interesse e composição e mais especificamente, os interesses literários e filosóficos do psicanalista vienense. A ambiguidade se deve parcialmente ao próprio Freud, interessado, justamente, em certa aura de autonomia e originalidade para a sua obra. 0 cientista incompreendido, injustiçado, solitário, desbravador do campo do inconsciente, aparece diante de nós como se fosse um retrato pintado por Caspar David Friedrich (1774-1840). Mas, exceto pelos exageros, e até por causa deles, é possível vislumbrar muito dessa complexa personagem chamada Freud nas cartas a Fliess apresentadas e comentadas no livro "Aus den Anfängen der Psychoanalyse". Do mesmo modo, nos "Estudos sobre a histeria", temos uma imagem dessa situação na discussão promovida por Freud do caso de Elisabeth Von R. Diz-nos Freud:

Não fui sempre um psicoterapeuta, mas sim fui educado, como outros neuropatologistas, para empregar diagnósticos locais e eletroprognósticos, e ainda me causa estranheza que os relatos de casos que escrevo pareçam contos [Novellen] e que, como se poderia dizer, falta-lhes o selo de seriedade conferido ao que é científico ${ }^{17}$.

É curioso nesse trecho da citação, encontrada logo no início da epícrise, o reconhecimento das características do relato como uma narrativa de caráter ficcional, poética, e que, como tal, afastar-se-ia do caráter científico exigido de um relato de caso. Esse tipo de preocupação anunciada de modo tão precoce nesse texto, e, em parte, talvez desnecessária, sempre esteve, no entanto, no cerne das críticas à psicanálise, como aquela de Popper, de que a psicanálise não seria refutável, não seria científica, já que não há ciência do particular. Nesse sentido, critica-se que as generalizações de Freud sempre acabam em opiniões de caráter poético, sendo mais afeitas à arte e ao fantasiar dos poetas, do que propriamente à suposta objetividade da ciência. Foi para se proteger dessas críticas e até mesmo as antecipando que Freud introduz a sua discussão de caso. A argumentação de Freud em defesa dessa linguagem algo literária e imaginativa é a seguinte:

\footnotetext{
${ }^{17}$ FREUD, S, Das Werk, Epikrise, p.131. 0 texto original diz o seguinte: "Ich bin nicht immer Psychotherapeut gewesen, sondern bin bei Lokaldiagnosen und Elektroprognostik erzogen worden wie andere Neuropathologen, und es berührt mich selbst noch eigentümlich, daß die Krankengeschichten, die ich schreibe, wie Novellen zulesen sind, und daß sie sozusagen des ernsten Gepräges der Wissenschaftlichkeit entbehren".
} 
Tenho de consolar-me com a reflexão de que a natureza do objeto [Natur des Gegenstandes] é evidentemente a responsável por isso, mais do que alguma predileção minha. A verdade é que o diagnóstico local e as reações elétricas não levam a parte alguma no estudo da histeria, ao passo que uma apresentação [Darstellung] pormenorizada dos processos anímicos [seelischen Vorgänge], como as que estamos acostumados a encontrar nas obras dos poetas, me permite, com o emprego de algumas fórmulas psicológicas, obter pelo menos alguma espécie de compreensão [Einsicht] sobre o curso dessa afecção. Os casos clínicos dessa natureza devem ser julgados como psiquiátricos; entretanto, possuem uma vantagem sobre estes últimos, a saber: uma ligação íntima entre a história dos sofrimentos do paciente e os sintomas de sua doença - uma ligação pela qual ainda procuramos em vão nas biografias das outras psicoses $[\text { Psychosen }]^{18}$.

Não levem excessivamente a sério o uso impreciso do termo "psicoses" nesseperíodo das elaborações freudianas. 0 que gostaria que ficasse em relevo é o argumento de que a descrição fria do fato científico é infrutífera quando o assunto tratado abrange a natureza e o funcionamento do psiquismo recalcado, o que ele chama de "processos anímicos". Nesse sentido, Freud entende que uma descrição dos fatos à maneira de um conto, na medida em que corresponde à narrativa de uma história de vida somada aos seus aspectos psicológicos tanto individuais e empíricos quanto estruturais e, por decorrência, disposicionais, apresenta uma efetividade e utilidade maiores no que concerne à apresentação do tratamento realizado e de suas consequências efetivas. 0 principal motivo alegado pelo psicanalista vienense nesse sentido é a "ligação íntima entre a história dos sofrimentos do paciente e os sintomas de sua doença". A evolução clínica do caso, em contraste com a história da formação dos sintomas e das limitações causadas por eles compõem a narrativa.

\footnotetext{
18 FREUD, S., Das Werk, Epikrise, p.131. O texto original diz o seguinte: "Ich muß mich damit trösten, daß für dieses Ergebnis die Natur des Gegenstandes offenbar eher verantwortlich zumachen ist als meine Vorliebe; Lokaldiagnostik und elektrische Reaktionen kommen beidem Studium der Hysterie eben nicht zur Geltung, während eine eingehende Darstellung der seelischen Vorgänge, wie man sie vom Dichter zu erhalten gewohnt ist, mir gestattet, bei Anwendung einiger weniger psychologischer Formeln doch eine Art von Einsicht in den Hergang einer Hysterie zugewinnen. Solche Kranken geschichten wollen beurteilt warden wie psychiatrische, haben aber vorletzteren eines voraus, nämlich die innige Beziehung zwischen Leidensgeschichte und Krankheitssymptomen, nach welcher wir in den Biographien anderer Psychosen noch vergebens suchen".
} 
Naturalmente, podemos pensar que é justamente uma característica de Freud que permite a ele chegar a esse tipo de solução, por assim dizer inspirada. Essa característica é a sua evidente capacidade e versatilidade como escritor que utiliza propositalmente uma linguagem comum, palavras com carga afetiva e enfatiza características processuais dos casos, em detrimento da fria descrição estática de características e palavras neutras e termos latinos utilizados na literatura médica comum e que, numa traição demasiado irônica talvez, tornaramse a marca da Edição Standard Inglesa das "Obras Completas" de Freud. Nesse sentido, Bruno Bettelheim observa:

Não duvido de que os tradutores ingleses de Freud quiseram apresentar seus escritos ao público tão fielmente quanto possível - em função do quadro de referência dentro do qual desejavam que ele fosse entendido. Quando Freud parece ser mais impenetrável ou mais dogmático em tradução inglesa do que no original alemão, estar falando mais sobre conceitos abstratos do que a respeito do próprio leitor, e mais acerca da mente (mind) do homem do que de sua alma (soul), a explicação provável não é leviandade ou negligência por parte dos tradutores, mas um desejo deliberado de perceber Freud estritamente dentro do quadro de referência da medicina e, possivelmente, uma tendência inconsciente para se distanciarem do impacto emocional daquilo que Freud procurou transmitirin.

Argumentos semelhantes aos de Bettelheim, porém diferenciados sob alguns aspectos, foram também apresentados paralelamente por outros autores. ${ }^{20}$ Realmente, Brandtjá havia antecipado pontos importantes dessa crítica no início dos anos sessenta do século passado, ${ }^{21}$ quando Strachey ainda vivia, e antes do fechamento da Standard Edition.

Ernst Kris, em seu já mencionado prólogo ao livro que resgata as cartas à Fliess, entende essa característica de Freud como um "conflito intelectual" que afetou Freud no desenvolvimento de suas teses dos anos 90 do século XIX. De fato, trata-se de um conflito percebido por Freud em relação aos seus colegas médicos, mas Freud não parece estar de fato ele mesmo em conflito íntimo em relação a isto, mas, pelo contrário, defende a sua maneira de escrever. Já a própria psicanálise

\footnotetext{
${ }^{19}$ BETTELHEIM, B. Freud e a alma humana, p. 46.

20 Ver, sobretudo, MAHONY, 1982, e ORNSTON, 1982. Apud GUBRICH-SIMITIS, p. 11.

${ }^{21}$ Apud GUBRICH-SIMITIS, p. 11.
} 
anglo-alemã do pós-guerra não parece muito confortável em relação a isto, como atestam tanto o prólogo de Kris às cartas quanto a edição inglesa das obras na verdade incompletas de Freud. Teria sido interessante que tivessem feito como Rubens Rodrigues Torres Filho e tivessem batizado a compilação como "Obras Incompletas" e que, não menos importante, James Strachey tivesse adotado o mesmo rigor filológico com que Torres Filho fez suas traduções. Nesse sentido, esse Freud de Strachey segue um projeto anti freudiano de medicalização da linguagem do psicanalista vienense. A estética de Freud é decididamente polifônica e abrange delicadamente perspectivas que tencionam afetivamente os textos, $\mathrm{o}$ que, como diz Freud, dada a natureza da temática abordada, parece-lhe o mais adequado, talvez até mesmo a única maneira de abordar adequadamente os aspectos mais complexos da observação empírica e, não menos importante, da consideração teórica mais abrangente dos casos clínicos, de tal forma que assumam a dignidade de sua forma e âmbito como processos psíquicos ligados não apenas ao transitório e ao específico, mas também àquilo que é constante e perene no drama humano aos longo de períodos históricos consideráveis.

O que caracteriza as narrativas dos casos clínicos de Freud é a constante tensão entre os diferentes aspectos ligados à história do indivíduo, por um lado, às narrativas de casos empíricos, e, por outro, àquilo que diz respeito aos grandes movimentos ligados à história familiar, à herança cultural e biológica, à linguagem utilizada e à linguagem cifrada do inconsciente. A única forma que lhe parece mais coerente à característica psicológica dos casos é situar a tipicidade dos casos, pela adoção de um ambiente ficcional que produz o efeito pitoresco necessário à contemplação da forma que Freud pretende nos expor, que vai além da mera descrição e hierarquização de sintomas psíquicos de acordo com o quadro clínico caracterizado. $\mathrm{O}$ aspecto técnico e propriamente psiquiátrico aparece no interior da narrativa que, no entanto, apresenta um repertório emocionalmente muito mais amplo, constituindo, por assim dizer, um híbrido formal conciliador entre duas coisas muito díspares: 1) A riqueza emocional da fala poética ligada ao caso individual; 2) A precisão e a necessidade de método e resultado que caracterizam o trabalho científico. Nesse caso, o centauro se obtém pela descrição em forma de conto de um caso supostamente bem-sucedido de cura utilizando as caracterizações e manejos da histeria de acordo com a ciência que estavam 
tentando construir. A adoção dessa perspectiva artística na forma de exposição em nada desmerece a atitude científica de Freud, o que é atestado pela relevância que ainda hoje atribuímos à sua obra após quase oitenta anos de sua morte. E Freud, já em 1930, retoma as diferentes perspectivas do pesquisador empírico e do poeta, colocando-se como pesquisador empírico: "E bem podemos dar um suspiro, ao perceber que a alguns indivíduos é dado retirar sem maior esforço, do torvelinho dos próprios sentimentos, os conhecimentos mais profundos, aos quais temos de chegar em meio a torturante incerteza e incansável tatear."22 Mas, isso não nos autoriza a considerar que o psicanalista vienense estivesse limitado a uma linguagem meramente científica, muito pelo contrário, justamente porque ele tinha consciência da insuficiência daquilo que em Schopenhauer seria descrito como uma descrição dos fatos meramente de acordo com o princípio de razão, já que desse modo ele, como escritor, ficaria enredado no caudal da causalidade, nesse torvelinho de fenômenos observados na clínica, sem a criatividade que permitiria a ele uma síntese ou metáfora tão adequada quanto a dos poetas e artistas de um modo geral. Nesse sentido, a própria linguagem dos sonhos e dos sintomas, isto é, a linguagem do inconsciente, ela mesma condicionada por deslocamentos e condensações, sugeriu a Freud a abordagem a partir de uma posição de artista racional, o que é diferente do pesquisador empírico propriamente dito, pois aqui estamos falando da comunicação não apenas de sintomas e entidades nosográficas, mas de características afetivas concernentes à experiência psíquica das pacientes de Freud em seu processo de tratamento e de caracterizações muito precisas que apenas a linguagem dos artistas fornecem de um só golpe. Teríamos, com isso, um Freud que tira proveito tanto de intuições empíricas, conceitos e redes conceituais precisas, quanto também de um tipo de contemplação que extrapola o caso individual e, através de uma narrativa, de um conto, consegue transmitir aquilo que independe do transitório, por assim dizer, a sua "ideia platônica". Considero isso muito interessante para analisarmos a natureza filosófica da psicanálise, no sentido de que Freud precisa abarcar o conjunto de fatos clínicos, mas, também, ultrapassar os fatos e narrativas individuais que a clínica lhe apresenta e compreendê-los em seu conjunto.

22 FREUD, S. $O$ mal-estar na civilização, p. 66. 
Nas cartas de Freud percebemos como o tema da fantasia científica lhe é caro, por um lado, e o preocupa, por outro, na medida em que a referência ao empírico é ao mesmo tempo a exigência de imanência para o pensamento.

«Sie lieben also den Wahn wie sich selbst. Das ist Geheimnis» [Então eles amam a ilusão como a si mesmos. Este é o segredo]. Essa frase é retirada da correspondência de Freud a Fliess, mais precisamente no Manuscrito H (Paranoia). Ele foi enviado junto com o Manuscrito G na carta de 29 de Agosto de 1894. Como se sabe, nessas cartas surge a maioria dos temas que aparecerão sucessivamente na obra freudiana, e as coisas às vezes aparecem de modo singular e, por assim dizer, estabelecem o tom da teoria já em seus alicerces. Tais temas são, por exemplo: a realidade psíquica, a relação das pessoas com a verdade, a ampliação do conceito de sexualidade e a natureza sexual do sintoma psíquico, poéticas e narrativas no âmbito do trabalho científico (especialmente nos estudos sobre a histeria), um inconsciente dinâmico, a possibilidade de um tratamento psíquico para as neuroses, suas mudanças técnicas e o contexto da elaboração teórica e assim por diante. A inquietude científica de Freud permeia todos esses desenvolvimentos preliminares, tal como ocorrerá mais tarde até mesmo em suas obras tardias. Não quer dizer que de alguma outra forma não teríamos esse "tom" de Freud, mesmo que não tivéssemos conhecido essas cartas encontradas por Marie Bonaparte. Esse "tom" que nunca se alterou, não é senão a própria expressão daquilo que em Freud atua, também o que nele reage, o que o rege, o que vivifica essa sua pesquisa. Tanto assim que em 1939, novamente, quando ele escreveu "Moisés e monoteísmo", é ainda possível sentir esse mesmo questionamento apaixonado e essa tendência à fantasia, científica ou não.

Se a Psicanálise parece a muitos como um "sistema de crenças injustificadas"23, como diz MacIntyre, isso se deve à sua origem na autoanálise de Freud e na própria estrutura narrativa da qual surge também a partir da clínica freudiana, suas metáforas, condensações e deslocamentos. Essa construção artificial e experimental chamada Psicanálise assumiu ares de ciência, mas é em grande medida fruto da arte racional de Freud. Este, diante do abismo representado pela ausência de um conhecimento adequado do psiquismo humano,

${ }^{23}$ BORCH-JACOBSEN, M.; SHAMDASANI, S. Os Arquivos Freud: Uma Investigação Acerca da História da Psicanálise,p. 303. 
e, não podendo esperar eternamente pela consumação e bom acabamento desse conhecimento, faz tal como os poetas, e (por que não?) tal como a filosofia imanente de Schopenhauer, arriscando-se a formular hipóteses clínicas que tomam como ponto de partida especialmente a sua autoanálise, bem como a elaborar uma superestrutura teórica com ares schopenhauerianos, repleta de conceitos heurísticos. Freud está ciente desse fato. Ao final de seu "Estudo Autobiográfico" de 1925, ele escreve, falando de estruturas psíquicas:

Estas representações, e outras similares, pertencem a uma superestrutura especulativa [spekulativer Überbau] da psicanálise,em que cada parte pode ser sacrificada ou trocada sem dano nem remorso, a partir do momento em que uma insuficiência é constatada ${ }^{24}$.

A organização dos fatos clínicos é o que está na base dessa spekulativer Überbau, e Freud não pode fazer isso sem recurso à "bruxa”, já que é impossível ter uma referência in concreto de algo que é baseado na virtualidade de um funcionamento que não corresponde nem aos conhecimentos anteriores no campo do psiquismo e nem mesmo em sua observação direta. Por isso, ele recorre a diversos autores filosóficos, dentre os quais se destaca Schopenhauer, e teorias científicas, especialmente físicas (especialmente as de extração kantiana) e biológicas (especialmente as que nos conduzem a Lamarck, por um lado, e a Darwin, por outro), algumas francamente anacrônicas, e o recurso à linguagem da arte, especialmente, do ponto de vista de sua escrita, à narrativa dos contistas, pois estes conseguem tomar de um só golpe, como diz Schopenhauer, aquilo que os pobres homens de ciência demorariam séculos para alcançar. Essas lacunas da teoria psicanalítica são preenchidas por fantasias científicas, como ele diz nas cartas a Fliess, Abraham e Ferenczi, inteiramente de acordo com o programa kantiano anunciado na citação a seguir, proveniente da "Crítica da Razão Pura" e que designa o lugar a ser dado à psicologia empírica:

\footnotetext{
${ }^{24}$ FREUD, S. "Apresentação Autobiográfica" [Selbstdarstellung]. In: Das Werk, p. 58.0 texto original diz: "Solche und ähnliche Vorstellungen gehören zu einem spekulativen Überbau der Psychoanalyse, von dem jedes Stück ohne Schaden und Bedauern geopfert oder ausgetauscht werden kann, sobald eine Unzulänglichkeit erwiesen ist. Es bleibt genug zu berichten übrig, was der Beobachtung näher steht."
} 
Onde fica então a psicologia empírica, que desde sempre manteve o seu lugar na metafísica, e da qual o nosso tempo, depois de abandonar a esperança de estabelecer algo válido a priori quanto a isso, esperou tantas coisas grandiosas para o esclarecimento da metafísica? Respondo: ela aparece ali onde deve ser colocada a verdadeira doutrina empírica da natureza, a saber, ao lado da filosofia aplicada, cujos princípios a priori estão na filosofia pura; a qual, portanto, é ligada a ela, mas não pode ser a ela misturada ${ }^{25}$.

A Metapsicologia parece ser justamente esse esforço do psicanalista vienense de ultrapassar a metafísica feita através de meros conceitos (única reconhecida por Kant); ele tenta, de fato, fazer o que recomenda o filósofo de Königsberg, que é banir a psicologia empírica da metafísica, e talvez o contrário, que é banir a metafísica da psicologia empírica, já que aquela é considerada uma fantasia ligada a um inútil devaneio do conhecimento. De certa forma, para melhor conseguir realizar esse projeto, promove um movimento que não se mistura ao da metafísica imanente de Schopenhauer, mas o complementa, observando-o de perto (ainda que sem admitir publicamente a natureza e a importância desse movimento) e segue também seus próprios caminhos, na medida em que se trata de uma teoria voltada para a solução dos problemas práticos de sua clínica. Mas, para isso, precisa fazer recurso às metáforas e narrativas, exatamente como Schopenhauer, de acordo com o que Freud chama de "exposição metapsicológica"26. Tal exposição, que não se pretende metafísica, está já repleta dela, caso consideremos a noção de "metafísica imanente". Tais são os caminhos e descaminhos de Freud, o que explica, em grande medida, a admiração e reconhecimento em relação ao Freud escritor, e as críticas feitas a ele como homem de ciência.

\section{Referências bibliográficas}

BETTELHEIM, Bruno. Freud a Alma Humana. Cultrix: São Paulo., 1982.

BORCH-JACOBSEN, Mikkel; SHAMDASANI, Sonu. Os Arquivos Freud: Uma Investigação Acerca da História da Psicanálise. São Paulo : UNESP, 2014.

FONSECA, Eduardo Ribeiro da.Psiquismo e vida: Sobre a noção de Trieb nas obras de Freud, Schopenhauer e Nietzsche. Curitiba: Editora UFPR, 2012.

${ }^{25}$ KANT, I. Crítica da Razão Pura, p. 609.

${ }^{26}$ Conforme meu livro Psiquismo e Vida, p. 82. 
FREUD, Sigmund. Das Werk. Edição Eletrônica das Obras Completas. Berlin: Heptagon Verlag, 2010.

. Sexualleben. In: Sigmund Freud Studienausgabe. 11 vols. Band V. Frankfurt: S. Fischer Verlag, 1980. / 2. ed. Munique: DTV/de Gruyter, 1999. Edição Temática de Estudos.

SchriftenzurBehandlungstechnik.In: Sigmund Freud Studienausgabe. 11 vols. Ergänzungsband. Frankfurt: S. Fischer Verlag, 1980. / 2. ed. Munique: DTV/de Gruyter, 1999.

Aus den Anfängen der Psychoanalyse. [Organizada por Marie Bonaparte, Anna Freud e Ernst Kris.] Frankfurt amMain: Fischer, 1962.

The Standard Edition of the Complete Psychological Works of Sigmund Freud. London: Hogarth Press, 1999.

. Obras Completas. Tradução de José Luis Etcheverry. 18 vols. Buenos Aires: Amorrortu Editores, 1976.

Publicacionesprepsicanalíticas y manuscritos inéditos en vida de Freud (18861899). In: Obras Completas. Tradução de José Luis Etcheverry. 18 vols. Vol. I. Buenos Aires: Amorrortu Editores, 1976.

. Estudios sobre la histeria. J. Breuer e S. Freud. In: Obras Completas. Tradução de José Luis Etcheverry. 18 vols. Vol. 2. Buenos Aires: Amorrortu Editores, 1976.

Trabajos sobre técnica psicoanalítica, y otras obras (1911-1913). In: Obras Completas. Tradução de José Luis Etcheverry. 18 vols. Vol. 12. Buenos Aires: Amorrortu Editores, 1976.

Moisés y lareligión monoteísta. In: Obras Completas. Tradução de José Luis Etcheverry. 18 vols. Vol. 23. Buenos Aires: Amorrortu Editores, 1976. A correspondência completa de Sigmund Freud para Wilhelm Fliess(1887-1904). Rio de Janeiro: Imago, 1996.

O mal-estar na civilização. In: Obras completas. Vol. XVIII. Trad. e notas de Paulo César de Souza. São Paulo: Companhia das Letras, 2010.

GUBRICH-SIMITIS, Ilse. De volta aos textos de Freud. Rio de Janeiro: Imago, 1995.

KRIS, Ernst. Estudio preliminar. In: Los origenesdelPsicoanalisis. [AusdenAnfängen der Psychoanalyse]Madrid: Alianza, 1979.

KANT, Immanuel. Crítica da Razão pura. Trad. e notas de Fernando Costa Mattos. Petrópolis: Vozes, 2016.

LOPARIC, Zeljko. "De Kant a Freud: Um roteiro". Campinas, Revista Natureza Humana v. 5, n. 1, primeiro semestre de 2003, pp. 231-245.

NIETZSCHE, Friedrich. Genealogia da Moral: Uma Polêmica. Trad. e notas de Paulo César de Souza. São Paulo: Companhia das Letras, 1998.

.Obras Incompletas. Trad. e notas de Rubens Rodrigues Torres Filho. São Paulo: Abril Cultural, 1978.

SCHOPENHAUER, Arthur. MVR II (O mundo como vontade e representação: Complementos. Volumes 1 e 2.). Trad. e notas de Eduardo Ribeiro da Fonseca. Curitiba: Editora UFPR, 2014.

Recebido: $16 / 01 / 18$

Received: 01/16/18

Aprovado: 22/01/18

Approved: 01/22/18 